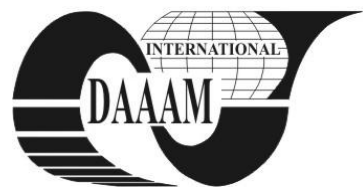

\title{
A CONTROL SYSTEM FOR MOBILE FORESTRY CABLEWAY WITH HYDROSTATIC DRIVES - WINDING DRUMS CONTROL
}

\author{
HUTAK, P[etr]; KLIMA, B[ohumil] \& PROCHAZKA, P[etr]
}

\begin{abstract}
The paper deals with wood logging problems and technology (Freedman et al., 1995), (Goldenberg et al., 1995), (Junmei et al., 2007) and (Papadopoulos \& Sarkar, 1997). The main part is focused on control of winding drums hydrostatic drives in forestry cableway. The cableway system description is introduced in another contribution. Proportionally controlled hydrostatic pumps are used for supplying hydrostatic motors for all winches of the cableway. Position and speed control is being performed for each winding drum. Pressure limiting is also required for each hydrostatic circuit. Although overpressure valves are present in hydrostatic circuits, pressure controller is necessary for adjustable pressure limiting during the cableway operation. There is a cascade control scheme with a parallel pressure controller. The pressure control of cableway drives is a key problem described in this paper.
\end{abstract}

Key words: forestry cableway, winding drums control, hydrostatic drives

\section{INTRODUCTION}

Cable mechanical systems produce a lot of oscillations and disturbances. Parameters of these systems can be changed during their operation by changing the cable length, loads, terrain profile etc. Partially suspended loads (the timber is hanged up on one its end, the second end of the timber skids sometimes on the ground, sometimes it hangs down swinging over the terrain during its transport) produce oscillations which are usually unpredictable in the control system. These oscillations cause force disturbances on the winch end of cable and are transfered to the measurable variables as pressure oscillations -the forces proportional to the pressure.

A dynamic pressure control is necessary to achieve a good performance of the cableway. There are two cables (mainline and haul-back line) which pull a carriage against each other. Therefore a good synchronization of these cables is necessary. A good pressure control is one of basic conditions for the synchronization.

Although the controller design is similar to an electric drive the mechatronic system containing cables brings some specific problems. The concept of individual winding drum control grew up in successive steps, on the basis of previously achieved results.

\section{HYDRAULIC DRIVE AND ITS CONTROL LOOP DESCRIPTION}

Pumps of all drives have common shaft and they are driven by combustion engine. Its fuel pump lever is controlled by a linear actuator with DC motor. Its speed is controlled according to carriage desired speed and calculated power of cableway drives.

The pump is driven by the current of its control coil. The hydrostatic motors can operate only with two discrete speedvalues (two speed gears) controlled by a binary signal. It can change discretely its number of turns per volume unit in ratio 1:2.5. The speed gear selection block switches the motor according to desired speed and measured pressure in cableway operating modes where synchronous operation of mainline and haul-back line is required. The motor has a magnetic impulse speed sensor on its shaft. A pressure sensor is in the hydraulic circuit. This sensor is placed in the branch of the hydraulic circuit, where the operating pressure is present when the cable is pulling.

The control scheme uses a cascade configuration similar to a position servo-drive.

The pump control coil is supplied by four-quadrant PWM switched transistor-bridge. Desired current of traction cables is given by a superior speed PI type controller. This controller has the desired speed on the input in speed mode or it can have next superior position $\mathrm{P}$ type controller with a variable speed limit. The position controller assures carriage stopping in safety point near the cableway tower and in stop points (in the automatic traversing mode).

Each drum drive has its own pressure controller in the control scheme. Its output affects the desired current from superior (speed or position) controllers. Outputs of both controllers are compared and the lower of them is used as the desired current.

\section{CONTROLLERS SYNTHESIS}

Current controller is set according to the optimum modulus method for a second order system. The first time constant is the coil time constant and the second one is the PWM substitution time constant.

Speed controller controls the speed of the drum. Proportionally controlled hydrostatic pump with hydrostatic motor represents a speed variator controlled by current into its control coil. For the speed controller synthesis we can assume second order transfer function with time constant of pump internal servomechanism and substitution time constant of speed sensor. The gain of this system is a ratio of drum speed and coil driving current. Definitely, the gain depends on the speed gear used in the hydro-motor. The designed controller is also PI type. It is set according to the optimum modulus method too. Its gain is switched together with speed gear of the hydromotor.

Pressure controller controls the cable force or provides pressure saturation. The pump transfer function includes the same time constant which is present in the speed controller synthesis. The gain is given by the ratio of produced oil volume to driving current. For the cableway mechanical system transfer function we assume that the end of cable is standing - its motion is negligible in relation to all othertime changes of other quantities (similarly a breaked electric motor is assumed for current controller synthesis, when induced voltage is neglected). Therefore the mechanical system has an integrating character and further the long cable behaves like a spring (with a significant oscillating component). The gain of the mechanic system is varying and it depends on the cable elasticity and on the unwound cable length. 
It is not possible to use a standard PID controller in this application. For stable operation it is simply very slow and useless. Therefore bang-bang controller without hysteresis was used. The controller is non-stable from its principle but very quick. This controller switches when pressure difference sign changes. When bang-bang controller was tested, pressure oscillations in hydraulic circuit had been reaching mostly $20 \%$ of the desired pressure. It is caused by the transfer function which has fourth order degree and has a big time constant. Therefore an alternative switching rule was implemented. The controller output switches when following switching line is crossed over:

$$
S=K \cdot X 2+X 1
$$

where

$X 1$ - pressure difference

$X 2$ - pressure difference derivation

$K$ - switching line angular coefficient

This controller is known as predictive bang-bang controller (Dodds, 1981), (Lucas \& Kaya,2002) and (Shaomian et al., 2007). Simulated trajectories in the phase plane are shown in fig. 1. - for the standard bang-bang controller and also for the used predictive controller. Also the switching lines for both controllers are shown in this figure. It is clear that predictive controller switches with a particular phase lead. The phase lead is given by the tend of the switching line. A significant suppression of the limit cycle magnitude is achieved using this controller. It is clear from Fig. 1. and Fig. 2. Fig. 2 represents step responses of closed pressure control loops for both compared controllers. Switching line inclination $K$ was set experimentally.

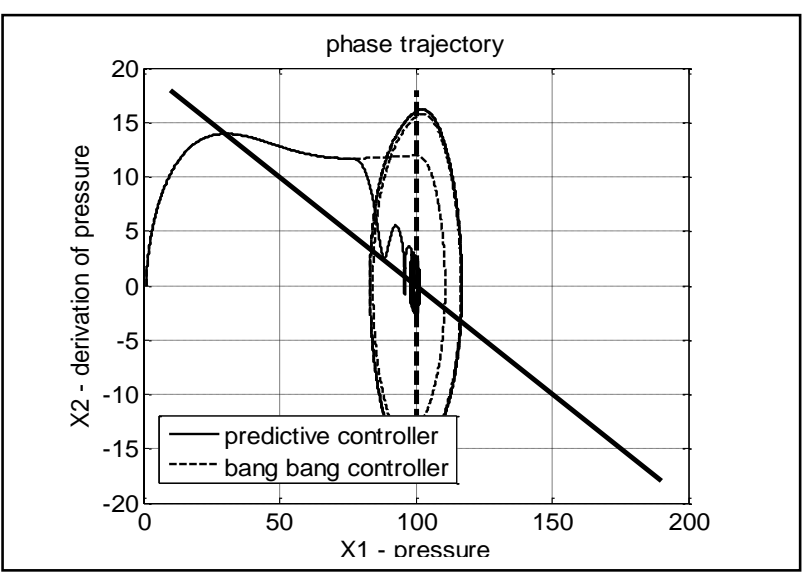

Fig. 1. Phase trajectories and switching lines of standard bangbang controller and of predictive controller. Simulation results are presented

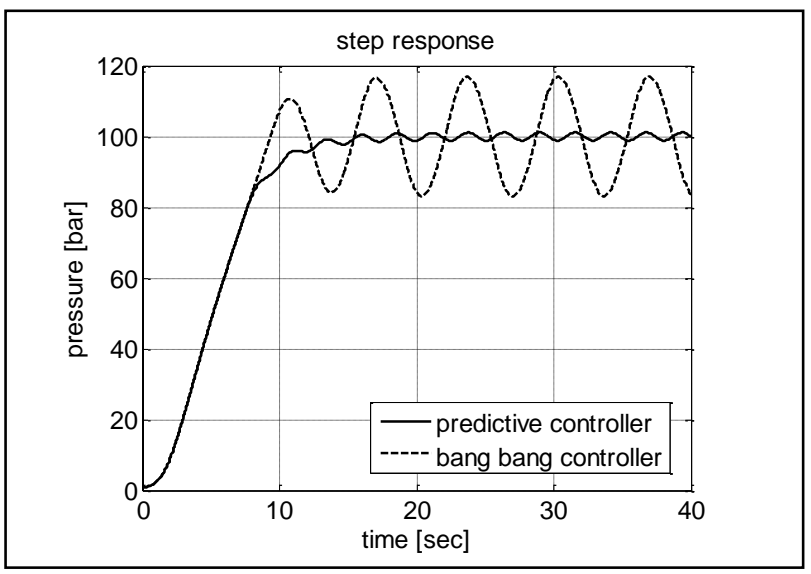

Fig. 2. Pressure step responses when standard bang-bang controller or predictive controller are used. Simulation results are presented

\section{CONCLUSION}

A control scheme and issues of cable winding drum drive control in a forestry cableway system are described in this paper. The hydrostatic drive has similar features such as a common electric drive. The controller synthesis is done in a similar way. The presence of tensioned oscillating of long cables is a key problem of the control. These cables produce oscillations which must be necessarily compensated by a high speed pressure controller. One of well-functioning solutions is using the predictive bang-bang controller. This controller has a suppressed magnitude of the limit cycle and it is able to damp cable mechanical oscillations very well.

A precision pressure control or limiting is necessary for good function of the superior control structure. Traction cables of the cableway need to be perfectly synchronized during the carriage traversing. The cableway control system was developed and it successfully passed field tests.

Work on this issue will continue to develop control algorithms for proportional hydro-motors which will replace the current "two step" hydro-motors used in this forestry cableways.

\section{ACKNOWLEDGEMENTS}

The contribution was partially supported by projects CZ.1.05/2.1.00/01.0014 "Center for Research and Utilization of Renewable Energy Sources" of the Ministry of Education, Youth and Sports of the Czech Republic and MSM 0021630516 of the Ministry of Education, Youth and Sports of the Czech Republic.

\section{REFERENCES}

Dodds, S.J. (1981). Bang-bang control law for single-input time-invariant plant, Control Theory and Applications, IEEE, Vol. 128, No. 5., (September 1981), (227-232), ISSN 0143-7054

Freedman, P. Papadopoulos, E. Poussart, D. Gosselin, C. Courteau, J. (1995). Application of Robotic Technologies to Forestry Equipment, Electrical and Computer Engineering, Vol.2, (September 1995), (1140 - 1143), ISSN 0840-7789

Goldenberg, A.A. Wiercienski, J. Kuzan, P. Szymczyk, C. Fenton, R.G. Shaver, B. (1995). A remote manipulator for forestry operation, Robotics and Automation IEEE Transactions, Vol. 11, No. 2, (April 1995), (185 - 197), ISSN 1042-296X

Junmei Z, Wenbin L, Chao S, Deming W, Chua, P.S.K., Tan F.L. (2007). Development of a CPLD Based Wireless Remote Control System of Pruning Machine for Plantation Forest, Proceedings of Computer Supported Cooperative Work in Design, 2007. CSCWD 2007, Melbourne, Australia, ISBN 1-4244-0963-2, Weiming Shen (Ed.), pp. 1078 - 1081, Melbourne

Lucas, S.K. Kaya, C.Y. (2002). Switching-time computation for bang-bang control laws, Proceedings of American Control Conference, Vol. 6., June 2001, Arlington USA, ISSN 0094-2898, pp. 275 - 278, IEEE Service Cente, USA

Papadopoulos, E. Sarkar, S. (1997). The dynamics of an articulated forestry machine and its applications, Proceedings of Robotics and Automation IEEE nternational Conference, Vol.1., ISBN 0-7803-3612-7, pp. 323 - 338

Shaomian Ch., Jun Z., Jixin Q., (2007). A Design Method of Bang-Bang and PID Integrated Controller Based on Rough Set, Proceedings of Fuzzy Systems and Knowledge Discovery, Vol. 4., August 2007, Haikou, Hainan, China, ISBN: 978-0-7695-2874-8, pp. 525 - 533, Copyright Clearance Center, 222 Rosewood Drive, Danvers, USA 